Provided for non-commercial research and education use. Not for reproduction, distribution or commercial use.

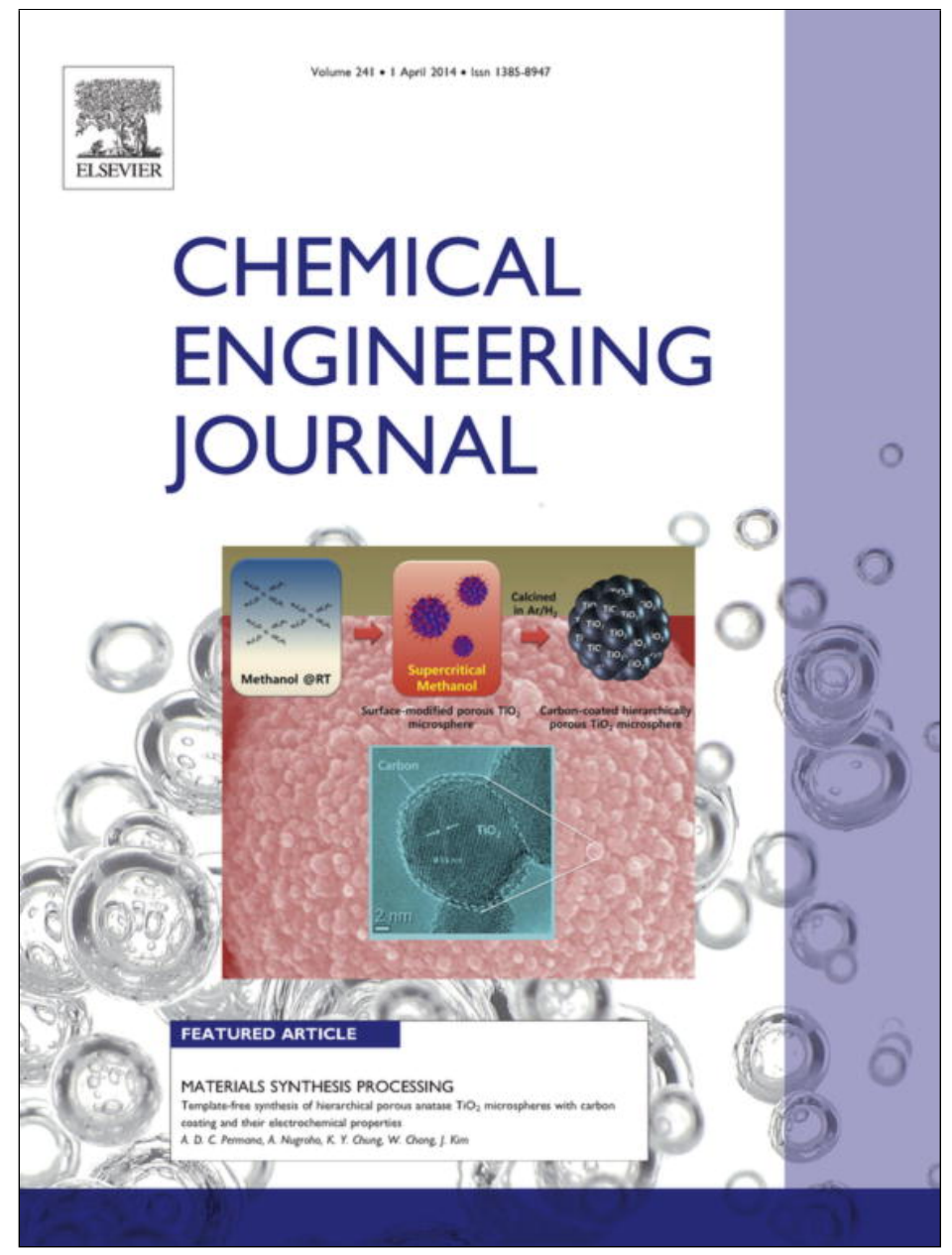

This article appeared in a journal published by Elsevier. The attached copy is furnished to the author for internal non-commercial research and education use, including for instruction at the authors institution and sharing with colleagues.

Other uses, including reproduction and distribution, or selling or licensing copies, or posting to personal, institutional or third party websites are prohibited.

In most cases authors are permitted to post their version of the article (e.g. in Word or Tex form) to their personal website or institutional repository. Authors requiring further information regarding Elsevier's archiving and manuscript policies are encouraged to visit:

http://www.elsevier.com/authorsrights 


\title{
Investigation on the montmorillonite adsorption of biocidal compounds incorporating thermodynamical-based multicomponent adsorption isotherm
}

\author{
L.K. Ong ${ }^{\text {a }}$, F.E. Soetaredjo ${ }^{\text {, }}$ A. Kurniawan ${ }^{\text {a }}$, A. Ayucitra ${ }^{\text {a }}$, Jhy-Chern Liu ${ }^{\mathrm{b}}$, S. Ismadji ${ }^{\text {a,* }}$ \\ ${ }^{a}$ Department of Chemical Engineering, Widya Mandala Surabaya Catholic University, Kalijudan 37, Surabaya 60114, Indonesia \\ ${ }^{\mathrm{b}}$ Department of Chemical Engineering, National Taiwan University of Science and Technology, No. 43, Sec. 4, Keelung Rd., Taipei City 106, Taiwan, ROC
}

\section{H I G H L I G H T S}

- Microwave power level determined the characters of organo-bentonite.

- Organo-bentonite increased the removal percentage of triclosan.

- Intercalated organic cation reduced the adsoption site for benzalkonium chloride.

- $\mathrm{pH}$ value affects the adsorption of benzalkonium chloride and triclosan.

- Incorporation of thermodynamical spontaneity ratio improved extended Langmuir model.

\section{A R T I C L E I N F O}

\section{Article history:}

Received 11 October 2013

Received in revised form 29 November 2013

Accepted 2 December 2013

Available online 11 December 2013

\section{Keywords:}

Adsorption

Benzalkonium chloride

Triclosan

Extended Langmuir

Organo-bentonite

\begin{abstract}
A B S T R A C T
Sublethal concentration of biocides, namely triclosan and benzalkonium chloride, have been known to raise severe environmental problems such as pathogens resistance and the existence of the toxic compounds in reclaimed water. Simple adsorption process of those biocides onto the bentonite modified by dodecyltricetyl ammonium bromide (DTAB) cation, show a remarkable increase on the removal efficiency of triclosan, regardless of the $\mathrm{pH}$ value. It was found that organophilic cation facilitates the anchoring of hydrophobic triclosan, but slightly limits the adsorption of benzalkonium chloride by occupying the active cation exchange site in the bentonite structure. Adsorption of a single system can be described properly by Langmuir isotherm equation. Incorporation of the Gibb's free energy on the affinity constant of the extended Langmuir equation may attribute robust predictive ability on the binary adsorption model.
\end{abstract}

(c) 2013 Elsevier B.V. All rights reserved.

\section{Introduction}

Biodegradation is a common part of the proper life cycle in this nature. However, in some cases, biodegradation is undesired for its destructive effect towards the natural products. In addition, the microbes, which have been acknowledged to be the main subject of this natural phenomenon, slowly release some toxic compounds, which are responsible for many diseases. To overcome those problems, human have invented several chemical compounds, the biocides, which can inhibit the metabolism, even eliminate the microorganisms. There are many biocides available today showing broad spectrum of antimicrobial activity, which may extend its application ranges.

Two types of commonly used biocides are benzalkonium chloride and triclosan, which can be classified as quaternary

\footnotetext{
* Corresponding author. Tel.: +62 31389 1264; fax: +62 313891267.

E-mail address: suryadiismadji@yahoo.com (S. Ismadji).
}

ammonium and chlorophenol compounds. Many consumer product, for example, cosmetic and cleaning products, also contain these compounds. Notably, benzalkonium chloride and triclosan are frequently found to be used in many household disinfection products. Those biocides are known to have a vast susceptibility range of microorganisms and non-corrosive properties; therefore, they have been utilized in many industries (i.e., food industries, textile industries, paper industries, oil and gas industries, plastic industries, etc.) to prevent biofouling in the pipelines and product deterioration.

A massive use of biocides in daily life generates a wastewater, which contains the excess of those biocides [1]. Although wastewater treatment plant has reduced much of those compounds, there are a number of biocides in the scale of $\mathrm{ng} / \mathrm{L}$ to $\mathrm{mg} / \mathrm{L}$ that still remaining [2-3]. Some researchers denote that sublethal concentration of remaining biocides found in the nature, particularly in the reclaimed water, may accumulate in the microbial cells and elicit microbial resistance on the biocides itself 
and some antibiotics, which may impact on the human health [4-6]. In the other hands, some toxic organic compounds such as the trihalomethanes, dioxins, and benzenes, which are known to be carcinogenic substances have been reported to be exist as the degradation products of those biocides and poisoning many aquatic organisms [7-9]. As the result, supplementary treatment process on the regular wastewater treatment plant should be involved to manage a maximum elimination of those hazardous residues.

Several processes have been proposed to remove those micropollutants such as $\mathrm{UV} / \mathrm{TiO}_{2}$ photocatalysis $[7,10]$, membrane bioreactor [11], chemical oxidation [12], chlorination [9,13], ozonisation [12,14], and activated carbon adsorption [14-15]. Amongst those processes, adsorption shows a promising prospect in removal efficiency and cost feasibility. However, the utilization of powdered activated carbon often raises a drawback on the cost of adsorbent. Bentonite, which has been known as a low cost and abundantly available natural adsorbent material in Indonesia, is mostly used in its form of organo-bentonite as alternative substitution of activated carbon to perform the adsorption of several organic moieties including antibiotic agents [16-17]. However, investigation on the adsorption of trace household biocide compounds in the water is still rare among all adsorption studies using pristine and organoclay.

In this study, the effect of microwave power output on the interlayer distance of organo-bentonite has been carefully examined to get an effective modification parameter, which can be used further to achieve high removal efficiency of biocides adsorption. Utilization of the saponin extract of Sapindus rarak pericarp was also tested as the promising green modification agent. This natural surfactant shows considerable possibility to substitute synthetic surfactant. Investigation on the fundamental mechanism of the biocide compounds adsorption at various $\mathrm{pH}$ and different montmorillonite surface condition may contribute key concept for a better understanding on the practical biocides removal. Finally, a novel extended Langmuir model incorporating thermodynamical spontaneity ratio was assessed to prove its ability in performing an easy and critical evaluation on the adsorption data of the binary system (i.e., benzalkonium chloride and triclosan).

\section{Materials and methods}

\subsection{Materials}

Benzalkonium chloride ( $\geqslant 95 \%$ ) and triclosan (HPLC Grade, $\geqslant 97 \%$ ) were acquired from Sigma Aldrich and Fluka, respectively. The molecular structure and some specific information of those biocide compounds are given in Table 1 . Dodecyltricethylammonium bromide (DTAB) ( $\geqslant 99 \%$ ), hydrogen peroxide solution (35\%), hydrochloric acid $(37 \%)$, and sodium hydroxide $(\geqslant 98 \%)$ were obtained from Sigma-Aldrich, Singapore and used as-supplied. Tropical fruit of Sapindus rarak was collected from Klaten, Central
Java, Indonesia and extracted using the same procedure that was reported previously [18].

\subsection{Preparation of organo-bentonite}

Bentonite was obtained from a mining site located on Pacitan, East Java, Indonesia. Prior to the use, bentonite was purified by means of $0.5 \% \mathrm{H}_{2} \mathrm{O}_{2}$ solution with an impregnation ratio of $1: 10$ $(\mathrm{w} / \mathrm{v})$ for $24 \mathrm{~h}$ under a mechanical stirring at $200 \mathrm{rpm}$. The resulting bentonite was filtered, dried at $373.15 \mathrm{~K}$ for $24 \mathrm{~h}$, crushed, and screened with $100 / 120$ sieves to obtain the size fraction between $125 \mu \mathrm{m}$ and $152 \mu \mathrm{m}$. The cation exchange capacity (CEC) of the bentonite was measured according to the ASTM C837-99 procedure and found to be $39.5 \mathrm{meq} / 100 \mathrm{~g}$ bentonite.

Organo-bentonite was engineered by referring on this following procedure: $50.0 \mathrm{~g}$ of bentonite was dispersed in the $250 \mathrm{~mL}$ of distilled water containing surfactant (i.e., DTAB or saponin) with the amount equivalent to 1.5 times of the CEC of pristine bentonite. The suspension was stirred at $500 \mathrm{rpm}$ for $15 \mathrm{~min}$ and then subjected into a microwave oven at the heating power of 450,810 and $900 \mathrm{~W}$ for $60 \mathrm{~s}$. The organo-bentonite was repeatedly washed with distilled water to remove the excess of surfactant and dried in an oven at $105^{\circ} \mathrm{C}$ for $24 \mathrm{~h}$. Dried lump of organo-bentonite was crushed and sieved through $-100 /+120$ mesh screen. Organo-bentonite that was fabricated by using synthetic surfactant (i.e. DTAB) was labeled as DTA-bentonite, while the one that used saponin was S-bentonite.

\subsection{Characterizations of the pristine and organo-bentonite}

The Brunner-Emmet-Taylor (BET) specific surface area, pore volume, and average pore diameter of the original and organobentonite were quantified from nitrogen adsorption-desorption isotherms performed in a Micromeritics ASAP-2010 volumetric sorption analyzer at $77.15 \mathrm{~K}$ over a relative pressure $\left(p / p^{0}\right)$ range of $10^{-5}$ to 0.995 . Prior to the analyses, the samples were degassed in a vacuum condition at $423.15 \mathrm{~K}$ for $24 \mathrm{~h}$.

The powder X-ray Diffraction (XRD) patterns of the samples were taken by XRD Philip Expert Diffractometer at $30 \mathrm{kV}$ and $15 \mathrm{~mA}$ with a Ni-filtered $\mathrm{Cu} \mathrm{K} \alpha$ radiation $(\lambda=1.54056 \AA)$ at a step size of $0.01^{\circ}$. Fourier Transform Infra Red (FTIR) analysis was also performed to identify the surface functional groups of the bentonite before and after modification. The analysis was conducted in a Shimadzu FTIR-8400S spectrophotometer based on the $\mathrm{KBr}$ disk method with cumulative scans of 200 . The spectra data of the samples were recorded in a wavenumber range of $4000-500 \mathrm{~cm}^{-1}$.

To understand the surface charge behavior of the pristine, synthetic organo-bentonite, and natural organo-bentonite in the water, $\mathrm{pH}_{\mathrm{pzc}}$ (point of zero charge) of all samples were analyzed using the $\mathrm{pH}$-drift procedure [19], and found to be $2.92,3.12$ and 3.08 , respectively.

Table 1

Physical and chemical information about benzalkonium chloride and triclosan.

\begin{tabular}{|c|c|c|}
\hline & Benzalkonium chloride & Triclosan \\
\hline Molecular structure & 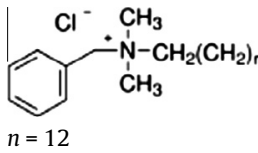 & $\mathrm{Cl}$ \\
\hline Physical state & White solid & White solid \\
\hline Molecular mass (g/mol) & 360 & 289.54 \\
\hline Chemical formula & {$\left[\mathrm{C}_{22} \mathrm{H}_{40} \mathrm{~N}\right] \mathrm{Cl}$} & $\mathrm{C}_{12} \mathrm{H}_{17} \mathrm{Cl}_{3} \mathrm{O}_{2}$ \\
\hline Water solubility, $25^{\circ} \mathrm{C}(\mathrm{g} / \mathrm{L})$ & 100 & 12 \\
\hline $\mathrm{p} K_{\mathrm{a}}$ & - & 7.9 \\
\hline
\end{tabular}




\subsection{Adsorption experiments}

Stock solution of benzalkonium chloride (BAC) and triclosan (TCS) were prepared at the concentration of $20 \mu \mathrm{mol} / \mathrm{L}$ by dissolving $7.2 \mathrm{mg}$ of BAC or $5.8 \mathrm{mg}$ of TCS into a litre of distilled water. Adsorption isotherm experiments of the single system were conducted by introducing various mass of adsorbent into a series of conical flasks containing $100 \mathrm{~mL}$ of the stock solution (i.e., benzalkonium chloride or triclosan solution) with a certain $\mathrm{pH}$ value that gave relatively maximum adsorption of both species. The $\mathrm{pH}$ value was previously determined at the $\mathrm{pH}$ range of 2-9 by an appropriate addition of $0.1 \mathrm{~N} \mathrm{HCl}$ or $\mathrm{NaOH}$ solution into the solution. For the next step, the flasks were shaken at various temperature ( $303.15 \mathrm{~K}, 313.15 \mathrm{~K}$ and $323.15 \mathrm{~K}$ ) within the equilibrium time $(1 \mathrm{~h})$ in a Memmert shaking water bath. The solution was then centrifuged in a Hettich EBA-20 centrifugal separator at $4000 \mathrm{rpm}$ for $5 \mathrm{~min}$ to separate the suspended solid particles. The residual concentration was measured using a Shimadzu UV/Vis-1700 spectrophotometer at the maximum wavelength of $256.8 \mathrm{~nm}$ for BAC and $277.9 \mathrm{~nm}$ for TCS. Adsorbed biocide at equilibrium condition per unit mass of adsorbent $\left(q_{e}\right)$ was calculated using this following equation:

$q_{e}=\frac{\left(C_{0}-C_{e}\right)}{m} \times V$

where $q_{e}$ are the equilibrium capacity of BAC or TCS on the adsorbent ( $\mu \mathrm{mol} / \mathrm{g}$ ), $C_{0}$ and $C_{e}$ symbolize the initial and equilibrium concentrations of adsorbate in the solution $(\mu \mathrm{mol} / \mathrm{L}), m$ is the mass of the adsorbent used ( $\mathrm{g}$ ), and $V$ is the volume of the effluent $(\mathrm{L})$.

To make a binary solution system, a known amount of benzalkonium chloride ( $7.2 \mathrm{mg}, 5.4 \mathrm{mg}$ or $3.6 \mathrm{mg}$ ) was added into $1 \mathrm{~L}$ of the triclosan solution with a concentration of $20 \mu \mathrm{mol} / \mathrm{L}$. The binary adsorption experiment was then conducted under the same condition as the single system. The equilibrium concentration of each biocide was measured using the multicomponent photometric mode, which is available within the same spectrophotometer apparatus.

\section{Results and discussion}

\subsection{Characteristics of the adsorbents}

Modification of bentonite using synthetic DTAB and natural saponin surfactant under microwave irradiation certainly change the genuine characteristics of the bentonite. Table 2 encloses the effect of the microwave irradiation power level towards the characteristics of the produced organo-bentonite in this study. It is obvious that the specific surface area $\left(S_{\mathrm{BET}}\right)$ and the total pore volume $\left(V_{\mathrm{T}}\right)$ of the organo-bentonite are dramatically decreased along with the increase of the microwave power level. These reveal that higher microwave irradiation power facilitates more blockades of some internal pores by means of the organic modifier that may hinder the sorption of $\mathrm{N}_{2}$ molecules. The other analogue evidence of the pore blockade is the diminishing of the sharp $\mathrm{N}_{2}$ desorption hysteresis loop (refer to Fig. S1 of Supporting Information) in the organo-bentonite (i.e., DTA-bentonite and S-bentonite) compared to that of the pristine one. A slight shift on the average pore size diameter approximately about $0.1-0.2 \mathrm{~nm}$ in organo-bentonite corresponding to the blockade of micropore by the intercalated organic cation can also be seen in the Barrett-Joyner-Halenda (BJH) pore size distribution curves (inset of Fig. S1).

The infrared spectral assignments of pristine and organobentonite are enlisted in Table S1. Several typical infrared absorption bands of montmorillonite mineral are similarly observed on the pristine and organo-bentonite. Those bands are $\mathrm{O}-\mathrm{H}$ stretching, which corresponds to the structural hydroxyl groups located at the surface and along the broken edges of tetrahedral sheets, $\mathrm{O}-\mathrm{H}$ bending vibrations of the hydroxyl group in adsorbed water molecules, Si-O stretching, $\mathrm{Al}-\mathrm{Al}-\mathrm{OH}$ bending vibration, $\mathrm{Al}-\mathrm{O}-\mathrm{Si}$ bending vibration, and $\mathrm{Si}-\mathrm{O}-\mathrm{Si}$ bending vibration. These results suggested that the tetrahedral-octahedral-tetrahedral layered sheets of the pristine bentonite remains intact even after the organic modification treatment. The intercalation of organic cation into the interlayer spacing of DTA-bentonite and S-bentonite can be observed by the absorption peaks of $\mathrm{C}-\mathrm{H}$ stretching at wavenumbers of $2900-2800 \mathrm{~cm}^{-1}$ and $\mathrm{C}-\mathrm{H}$ bending vibration at $1500-1400 \mathrm{~cm}^{-1}$. The existence of the acetyl group of S-bentonite in the IR pattern is also observed at $1712 \mathrm{~cm}^{-1}$.

Organic cation insertion may also impart an effect to the basal spacing of the bentonite. As shown in Table 2, reflection peak of the XRD pattern is shifted to the lower angle as the raise of microwave power level. In the beginning, a (001) reflection is seen at the $2 \theta$-angle of $6.32^{\circ}$, ascertaining the basal spacing of $1.40 \mathrm{~nm}$ while after the modification, the basal spacing is seen to be enlarged up to 2.24 and $2.27 \mathrm{~nm}$ at the largest microwave power output for the DTA-bentonite and S-bentonite, respectively. These results indicate the formation of pseudotrimolecular layer of alkyl chains, which consists of three alkyl chains forming a parallel interlocked array in the interlamellar space of the bentonite by the cation exchange mechanism between inorganic native cation of the bentonite and organic cation of DTAB or saponin. The existence of other peaks in the XRD patterns, such as quartz $(Q)$, calcite $(C)$, and feldspar $(F)$ remains unchanged during the microwave induced organic modification treatment. Those XRD patterns of pristine and representation of organo-bentonite (DTA-bentonite and S-bentonite) can be found in Fig. S2 of Supporting Information section. Therefore, the surface chemical of the bentonite has been changed from hydrophilic to more organophilic by increasing microwave power level, which is more suitable to adsorb organic compounds.

\subsection{Effect of $\mathrm{pH}$ to the adsorption}

The $\mathrm{pH}$ of the solution system contributes a crucial influence on the surface charge density of the bentonite and the ionization of

Table 2

The characterization results of pristine bentonite and the organo-bentonite produced at the different microwave power output level.

\begin{tabular}{|c|c|c|c|c|}
\hline Bentonite & $d(001)(\mathrm{nm})$ & $S_{\mathrm{BET}}\left(\mathrm{m}^{2} / \mathrm{g}\right)$ & VT $\left(\mathrm{cm}^{3} / \mathrm{g}\right)$ & Average pore diameter $(\mathrm{nm})$ \\
\hline Pristine bentonite & 1.40 & 47.48 & 0.118 & 6.11 \\
\hline \multicolumn{5}{|l|}{ DTA-bentonite } \\
\hline \multicolumn{5}{|l|}{ Power output (W) } \\
\hline 450 & 2.10 & 14.09 & 0.035 & 6.27 \\
\hline 810 & 2.22 & 10.87 & 0.027 & 6.29 \\
\hline 900 & 2.24 & 10.47 & 0.026 & 6.32 \\
\hline \multicolumn{5}{|l|}{ S-bentonite } \\
\hline \multicolumn{5}{|l|}{ Power output (W) } \\
\hline 450 & 2.11 & 13.28 & 0.033 & 6.24 \\
\hline 810 & 2.24 & 9.66 & 0.024 & 6.28 \\
\hline 900 & 2.27 & 8.86 & 0.022 & 6.31 \\
\hline
\end{tabular}


the adsorbate species, which may affect the removal effectivity. Based on the information in Table 1, the only adsorbate species that can be affected by $\mathrm{pH}$ is TCS, which has a $\mathrm{p} K_{\mathrm{a}}$ value of 7.9, while BAC, which has ionized instantly as a salt in the water, forms a stable positively charged quaternary ammonium cation that can never be affected by the $\mathrm{pH}$. However, the experimental result on the $\mathrm{pH}$ effect, which is described in Fig. 1, shows that the $\mathrm{pH}$ of the solution system still has some role in the adsorption of BAC.

In Fig. 1, the adsorption of BAC by either pristine or organobentonite is seen to increase for the $\mathrm{pH}$ value of 2-6 and then reach a plateau at the $\mathrm{pH}$ above 7 while the adsorption of TCS shows a relatively stable uptake at the acidic condition and goes down gradually from neutral $\mathrm{pH}$. This trend could be explained by the interaction between the surface charge of the bentonite and the ionic state of the adsorbate at the various $\mathrm{pH}$. At the low $\mathrm{pH}$, to be more precisely below $\mathrm{pH}_{\mathrm{pzc}}$ of the bentonite, a net repulsion between positively charged silanol and aluminol sites of montmorillonite crystallites and the quaternary ammonium cation takes place thus lowering the adsorbed BAC amount while for the TCS molecules, the adsorption is quite high due to the formation of the cation- $\pi$ interaction between the positively charged surface of the bentonite and partial negative charge of the aromatic ring within the TCS molecular structure. Right on the $\mathrm{pH}_{\mathrm{pzc}}$ of the bentonite, the neutral surface charge of the bentonite is occured, and this may nullify the net repulsion thus slightly increase the removal efficiency of BAC. The adsorption of TCS remains high because of the formation of hydrogen bonding between the aluminol and/or silanol with the phenolic group of the TCS molecule. At the higher $\mathrm{pH}$, which is above $\mathrm{pH}_{\mathrm{pzc}}$ of the bentonite, the surface becomes deprotonated and negatively charged. At this point, the adsorption of BAC rises to its peak due to the electrostatic attraction between the positive charged benzalkonium cation and the negatively charged surface; while the adsorption of TCS maintains its stability by the mechanism of anion- $\pi$ interaction between the negative surface of the bentonite and partial positive charge of the chlorobenzene group of the TCS molecule. Starting at the $\mathrm{pH}$ of 7, a gradual decline on the adsorption of TCS was occurred as the result of the partial ionization of the phenolic group within the TCS structure thus creating the anionic form of TCS that leads to the electrostatic repulsion with the surface of the bentonite.

The other remarkable case that can be noticed in Fig. 1 is the higher removal effectivity for the adsorption of TCS on the organo-bentonite and the lower one for the BAC. It can be implied that the exchange of interlayer inorganic cation with surfactant cation is responsible for the occurrence of this phenomenon. In addition to the expansion of the interlayer and basal spacing, the intercalation of surfactant cation in the clay may induce a unique degree of intermolecular attraction force, such as van der Waals

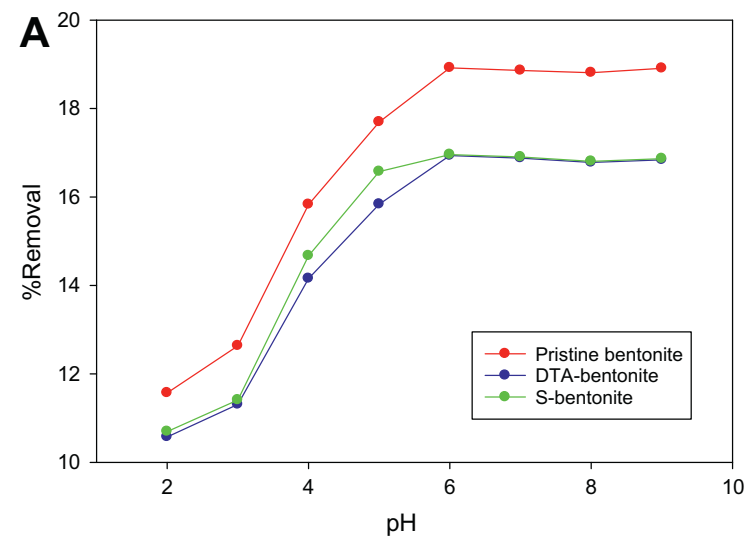

force with specific hydrophobic molecule, for example, TCS molecule in this study, which gives beneficial properties towards its adsorption process in spite of the constriction of its initial specific surface area and pore volume. On the contrary, BAC molecules, which may also serve as the organic cation in the solution system, have lost the most of possibility to form strong electrostatic attraction force due to the prior surfactant cation intercalation, leaving the weak van der Waals force as the single force that develops the adsorption. This force diminution leads to the abatement of its adsorption on the surface of organo-bentonite. However, it can be seen from Fig. 1 that the depression of the BAC removal is not so significant as the previous theory may reveal. This could be explained by the propensity of van der Waals attraction force that becomes larger for a larger molecules. The greater molecular weight of BAC compared to TCS contributes a greater van der Waals attraction force that may withstand the rate of the removal capacity reduction due to the loss of strong electrostatic force.

\subsection{Adsorption isotherms of a single component}

Up to date, there are many available adsorption isotherm models, which posses a number of parameters that can be used to describe the equilibrium adsorption of certain adsorbate. Among all isotherm equation, Langmuir and Freundlich isotherm equation have satisfactorily used for the evaluation of many adsorption systems. In most of the recorded adsorption studies, Langmuir isotherm has been well known to be superior against Freundlich isotherm in representing adsorption equilibria data since it featured the Henry's law limit at low concentration and possesses saturation capacity at high concentration domain. In contrast to the Langmuir isotherm, the lack of fundamental thermodynamics consideration in pure empirical Freundlich isotherm equation may form an infinite adsorption as the increasing equilibrium concentration value. Thereby, Langmuir may offer the simplest and most useful model for the best understanding of the both physical and chemical adsorption in gas and liquid systems.

The Freundlich equation was developed empirically for expressing an isothermic quantity of gas adsorbed by unit mass of adsorbent with pressure. The equation can be written as follows:

$q_{e}=K_{F} \times C_{e}^{1 / n}$

where $K_{F}$ is the Freundlich constant reflecting the adsorption affinity $\left[(\mu \mathrm{g} / \mathrm{g}) \cdot(\mathrm{L} / \mu \mathrm{g})^{-n}\right.$ or $\left.(\mu \mathrm{mol} / \mathrm{g}) \cdot(\mathrm{L} / \mu \mathrm{mol})^{-n}\right]$ and $n$ is a dimensionless intensity index of the surface heterogeneity degree. The adsorption favorability can be determined by judging on the $n$ values, whether it favorable $(2<n<10)$, moderately difficult

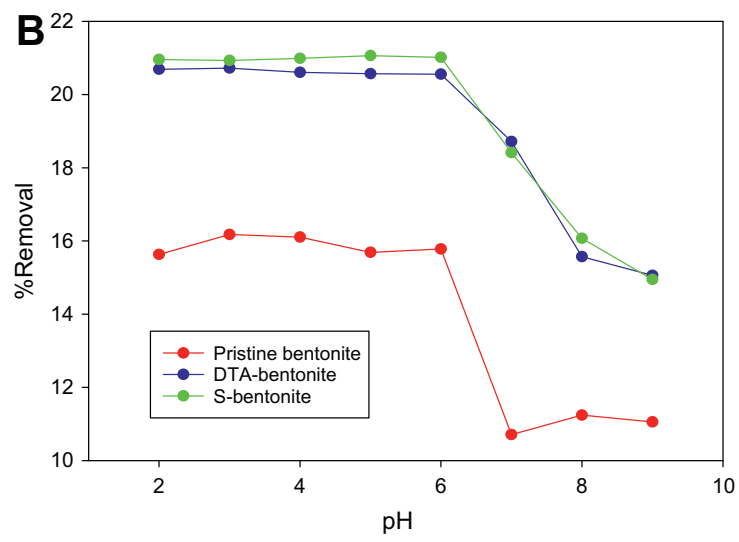

Fig. 1. Effect of the $\mathrm{pH}$ on the adsorption of benzalkonium chloride $(\mathrm{A})$ and triclosan $(\mathrm{B})$ onto the pristine bentonite, DTA-bentonite and S-bentonite ( $\mathrm{m}$ adsorbent $=0.1 \mathrm{~g}$, $T=303.15 \mathrm{~K}, t=1 \mathrm{~h})$. 
$(1<n<2)$ or poor $(n<1)$. The $n$ value that is higher than 10 indicates non-reversible behavior of the adsorption isotherms.

On the other side, Langmuir equation is essentially postulated from a simple equilibrium kinetic mechanism theoretical basis with several underlying assumptions, which state that the surface of the adsorbent has a fixed number of uniform site with identical adsorption enthalpy and affinity; the adsorbed molecules do not interact; the adsorption occurs through the same mechanism, and the adsorbed molecules can only form a monolayer on the outer surface of adsorbent. The mathematical expression of Langmuir isotherm is shown by the following equation:

$q_{e}=q_{m} \frac{K_{L} C_{e}}{1+K_{L} C_{e}}$

where $q_{m}$ is the Langmuir constant defining the maximum sorption capacity when the solid is covered with a monolayer $(\mu \mathrm{g} / \mathrm{g}$ or $\mu \mathrm{mol} / \mathrm{g}$ ) and $K_{L}$ is the adsorption affinity constant $(\mathrm{L} / \mu \mathrm{g}$ or $\mathrm{L} /$ $\mu \mathrm{mol})$. Those constants also can be used to determine the practical limit of the adsorption capacity and aid the identification of relative adsorption performance. By knowing those adsorption parameters, a dimensionless constant expressed by $R_{L}$, also can be calculated using a mathematical equation proposed by Weber and Chakravorti [20]:

$R_{L}=\frac{1}{1+K_{L} C_{0}}$

where $C_{0}$ is the initial concentration of adsorbate in the solution. The value of $R_{L}$ is useful to indicate the adsorption nature to be favorable $\left(0<R_{L}<1\right)$, unfavorable $\left(R_{L}>1\right)$, linear $\left(R_{L}=1\right)$, or highly favorable and non-reversible $\left(R_{L}=0\right)$.

Adsorption affinity $\left(K_{F}\right.$ and $\left.K_{L}\right)$ and the other parameter $\left(q_{m}\right.$ for Langmuir isotherm or $n$ value for Freundlich isotherm) may provide a glimpse of light to understand the occurring adsorption mechanism. At this present, there are three possible adsorption mechanism: physisorption, chemisorption or combination thereof. To distinguish the mechanism, quantification of adsorption heat is generally done. The distinct difference can be observed on the physisorption and chemisorption while the combination appears as the transitional value of those two. This thermodynamical principle, therefore, allows the temperature to affect the adsorption process.

Naturally, the adsorbed amount of adsorbate in physisorption shows a decreasing behavior towards the temperature increase, whereas on the chemisorption, the contrary result is found until a certain temperature is reached. This tendency may arise because of the fundamentally different existed bond formation between the physisorption and chemisorption, the weak intermolecular bond and strong chemical bond (i.e., ionic or covalent bond) formation. While the adsorption is usually an exothermic process due to reduction of surface entropy, higher temperature may lead to the desorption as prescribed by the principle of Le Chatelier but a fair requirement of activation energy in chemisorption phenomena, which is needed to be surpassed to form a chemical bond, promote the system to absorb a certain extent of thermal energy thus maintains the adsorption to increase spontaneously. Based on that, physisorption can be typically characterized by a decrease on the values of adsorption parameters along with the rising temperature while the chemisorption generally shows the opposite.

The correlation between experimental adsorption equilibrium data and the isotherm model was analyzed by applying nonlinear regression fitting in the SigmaPlot 11.0 software (Systat Software Inc.). Fig. 2 depicts the comparison of the fitting using Freundlich and Langmuir isotherm models on the single adsorption experiment data while the values of the fitted parameters are enlisted in Table 3. From the adsorption parameters evaluation, it is obvious that the values of constant $n$ show an erratic pattern and instead of increasing surface heterogeneity due to the intercalation of surfactant organic cation, the magnitude of constant $n$ for organobentonite is lower than that of the pristine-bentonite. In addition to that, the assessment of $R^{2}$ values also indicate that Langmuir isotherm describes experimental data better than Freundlich isotherm. Therefore, compared to Freundlich isotherm, Langmuir isotherm prevails as an excellent way to evaluate adsorption equilibria data for single component system.

As presented in Table 3 , the adsorption affinity $\left(K_{L}\right)$ and maximum adsorption capacity $\left(q_{m}\right)$ onto the pristine and organo-bentonite are diminishing with increasing temperature. This indicates that higher temperature facilitates the solubilization of adsorbate molecules in the solution thus preventing the adsorption. In addition, this phenomenon reveal that adsorption of BAC and TCS mainly occurs due to the physisorption. Although the adsorption of BAC onto the pristine bentonite theoretically takes place by the electrostatic attraction, which is identical to the chemisorption, the physisorption appears as the governing adsorption mechanism. This can be analyzed from the possible bonding strength that can be formed between the small amount of organic cation (dilute BAC concentration) and inorganic oxide anion on the montmorillonite surface. In dry montmorillonites, the bonding force between exchangeable cations and the montmorillonite sheets is relatively strong, but when the wet conditions occur, water is drawn into the interlayer space between sheets and causes the clay to swell dramatically thus weakens the bonding force [21]. All $R_{L}$ values assert that the adsorption of BAC and TCS are favored over the temperature range of this study.

\subsection{Thermodynamic parameters of the single system}

Thermodynamics aspect is useful to reveal the precise nature of the adsorption system. Thermodynamics parameters, such as activation energy $\left(E_{a}, \mathrm{~kJ} / \mathrm{mol}\right)$, the Gibb's free energy change $\left(\Delta G^{\circ}, \mathrm{kJ} / \mathrm{mol}\right)$, standard enthalpy change $\left(\Delta H^{\circ}, \mathrm{kJ} / \mathrm{mol}\right)$, standard entropy change $\left(\Delta S^{\circ}, \mathrm{kJ} / \mathrm{mol} \mathrm{K}\right)$, and isosteric heat of adsorption $\left(\Delta \mathrm{H}_{x}, \mathrm{~kJ} / \mathrm{mol}\right)$ cannot be obtained directly from the experiment but can be calculated from the adsorption data. The Gibb's free energy change has already known as the most fundamental criterion for the spontaneity of a process and its relation to the adsorption can be defined by the following equation:

$\Delta G^{\circ}=-R T \ln K_{D}$

where $R$ is the ideal gas constant $\left(8.314 \times 10^{-3} \mathrm{~kJ} \mathrm{~mol}^{-1} \mathrm{~K}^{-1}\right), T$ is the temperature $(\mathrm{K})$, and $K_{D}$ is the linear sorption distribution coefficient. The values of $K_{D}$ are simply obtained as the intercept of a straight line plot of $\ln \left(q_{e} / C_{e}\right)$ versus $C_{e}$ (figures are not shown), following Khan and Singh method [22]. The correlation of constant $K_{D}$ and Gibb's free energy change then can be reformed to an expression of standard enthalpy change and standard entropy change by applying the classical van't Hoff equation:

$\ln K_{D}=\frac{\Delta S^{\circ}}{R}-\left(\frac{\Delta H^{\circ}}{R}\right) \cdot \frac{1}{T}$

where the value of $\Delta H^{\circ}$ and $\Delta S^{\circ}$ are the slope and intercept of a linear fitting of $\ln K_{D}$ vs. $1 / T$, respectively.

Table 4 shows the values of the thermodynamic parameters for the adsorption of BAC and TCS. The negative values of the Gibb's free energy change exhibit that all adsorption occur spontaneously. The free energy change of adsorption $\left(\Delta G^{\circ}\right)$ was found to decrease with an increase in temperature indicating that higher temperature causes the adsorption process to be easier even though the $\Delta H^{\circ}$ value features a negative sign, which refers to an exothermic behavior of the adsorption process. This could be thermodynamically explained by the positive value of $\Delta S^{\circ}$ that reflects the strong 
Pristine bentonite

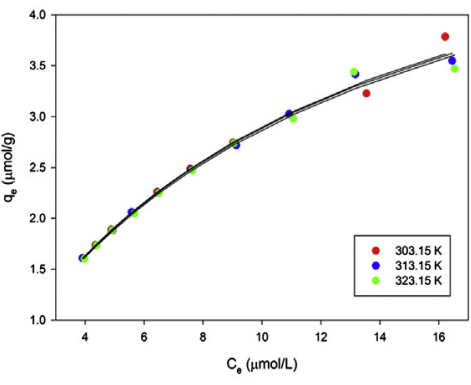

Langmuir
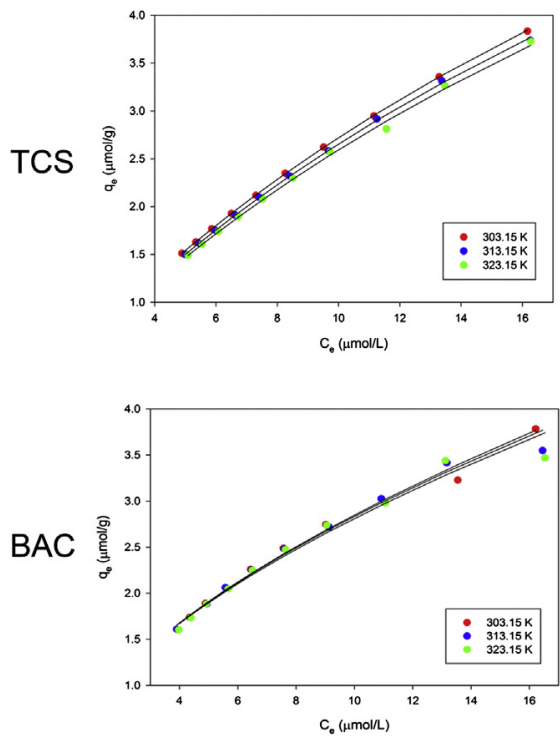

Freundlich

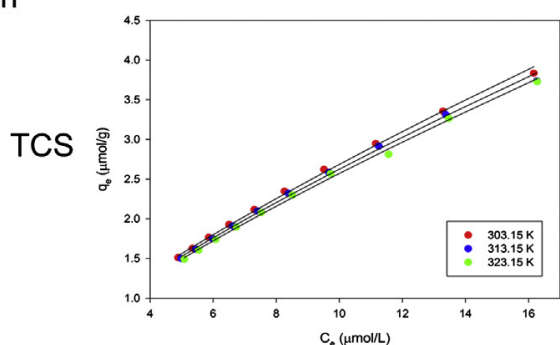

DTA- bentonite
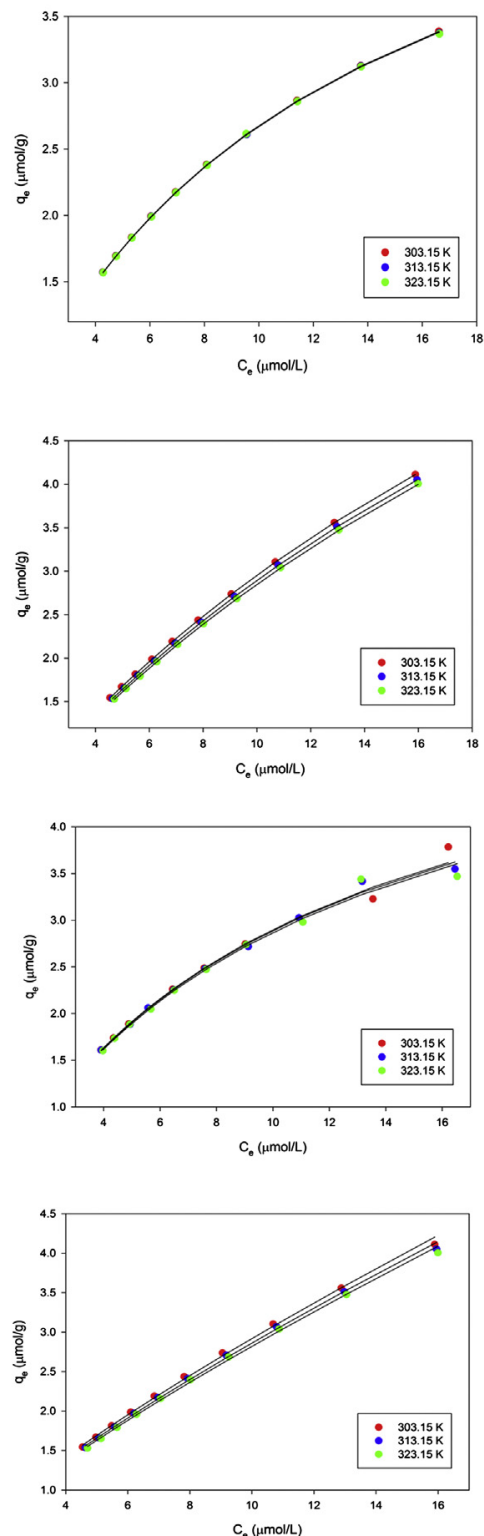
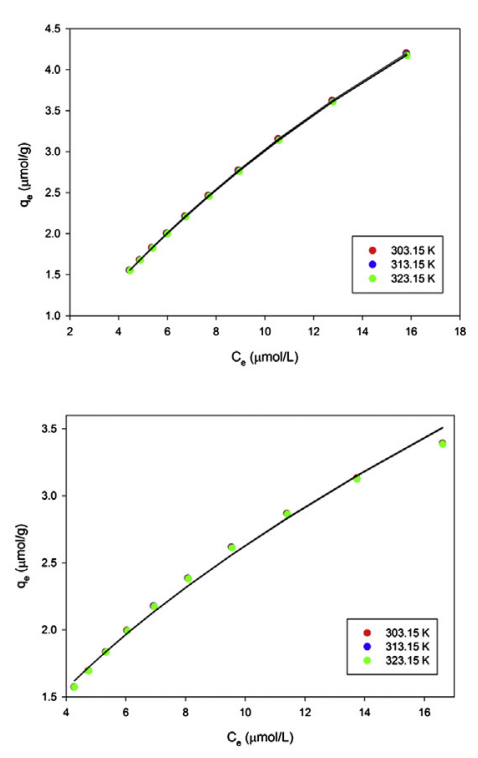

S- bentonite
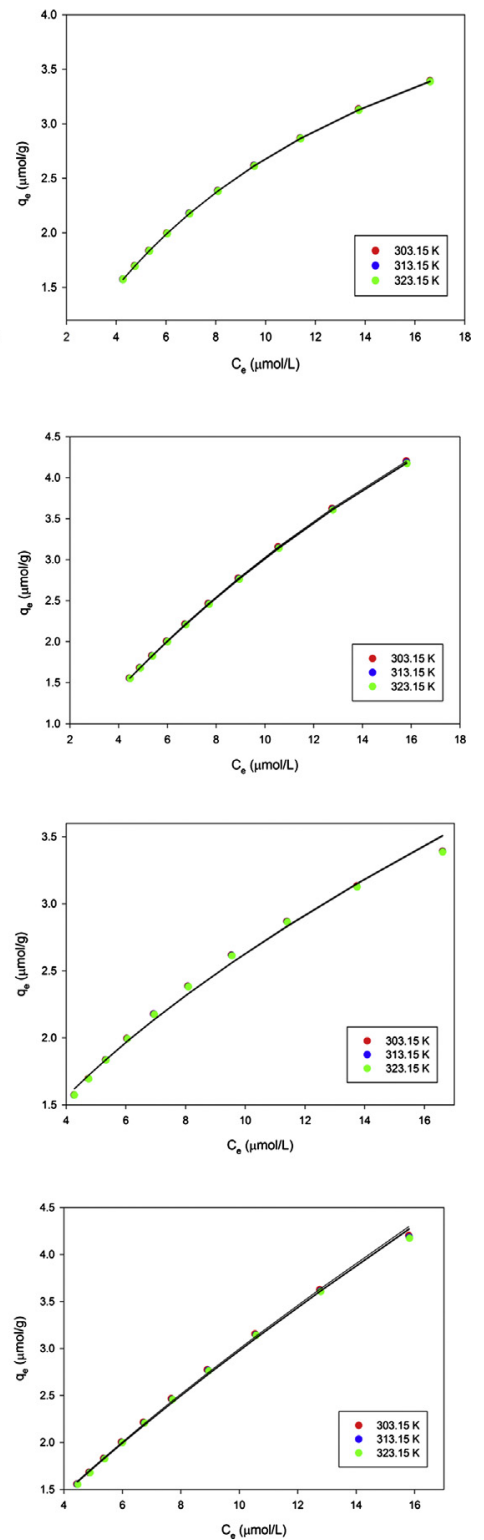

Fig. 2. Freundlich and Langmuir model fittings towards single adsorption data of benzalkonium chloride and triclosan on the pristine bentonite, DTA-bentonite and S-bentonite.

confinement of adsorbate species towards the sorption sites on the surface and the increased randomness at the solid-solution interface during the adsorption process. In addition, the increasing mobility of the adsorbate molecules in the solution with the temperature rise may intensify the adsorption chance of the adsorbate towards the surface.

In agreement with the evaluation of adsorption isotherm parameters, the magnitude of the negative Gibb's free energy change exhibits that the adsorption of TCS onto organo-bentonite solid is preferred rather than its adsorption onto the pristine bentonite at a given temperature while the adsorption of BAC is more favored on the pristine bentonite. Furthermore, the $\Delta H^{\circ}$ value indicates that the adsorption process truly belongs to physisorption (i.e., $\sim 20.9 \mathrm{~kJ} / \mathrm{mol}$ ), is not chemisorption (i.e., $80-200 \mathrm{~kJ} \mathrm{~mol}^{-1}$ ). These facts confirm that the thermodynamic parameters may have a strong correlation towards the adsorption isotherm parameters; therefore the parameters may be harnessed further in the modeling of multicomponent isotherm.

\subsection{Adsorption isotherms of a binary system}

Proper model of multi-component adsorption equilibria data may provide a complete description of the adsorption process in the practical application, yet, it is a challenging task to build it. Multicomponent adsorption is mainly controlled by the competition phenomena in the solution and/or the interface of the solid and the solution, which is hard to be incorporated to the isotherm equation due to its complexity. Thereby, most of the available empirical or semi-empirical adsorption models often lack of the theoretical basis and may not be able to accurately predict the adsorption behavior. It is undeniable too that to correlate multicomponent adsorption equilibria data 
Table 3

The adsorption parameters of Freundlich and Langmuir isotherm for single adsorption of benzalkonium chloride and triclosan.

\begin{tabular}{|c|c|c|c|c|c|c|c|c|c|}
\hline \multirow[t]{2}{*}{ Adsorbent } & \multirow[t]{2}{*}{ Adsorbate } & \multirow[t]{2}{*}{$T(\mathrm{~K})$} & \multicolumn{3}{|l|}{ Freundlich parameters } & \multicolumn{4}{|c|}{ Langmuir parameters } \\
\hline & & & $K_{F}(\mu \mathrm{mol} / \mathrm{g}) \cdot(\mathrm{L} / \mu \mathrm{mol})^{-n}$ & $n$ & $R^{2}$ & $q_{m}(\mu \mathrm{mol} / \mathrm{g})$ & $K_{L}(\mathrm{~L} / \mu \mathrm{mol})$ & $R^{2}$ & $R_{\mathrm{L}}$ \\
\hline \multirow{6}{*}{ Pristine bentonite } & \multirow{3}{*}{ Triclosan } & 303.15 & 0.4419 & 1.2756 & 0.85 & 11.6136 & 0.0306 & 0.99 & 0.9999 \\
\hline & & 313.15 & 0.4336 & 1.2786 & 0.84 & 11.4123 & 0.0303 & 0.99 & 0.9999 \\
\hline & & 323.15 & 0.4228 & 1.2756 & 0.84 & 11.1817 & 0.0302 & 0.99 & 0.9991 \\
\hline & \multirow[t]{3}{*}{ Benzalkonium chloride } & 303.15 & 0.7548 & 1.7329 & 0.98 & 5.9914 & 0.0939 & 0.99 & 0.3474 \\
\hline & & 313.15 & 0.7578 & 1.7455 & 0.98 & 5.9696 & 0.0938 & 0.99 & 0.3477 \\
\hline & & 323.15 & 0.7603 & 1.7605 & 0.97 & 5.9331 & 0.0937 & 0.99 & 0.3479 \\
\hline \multirow[t]{6}{*}{ DTA-bentonite } & \multirow{3}{*}{ Triclosan } & 303.15 & 0.4767 & 1.2706 & 0.87 & 12.3287 & 0.0315 & 0.99 & 0.6135 \\
\hline & & 313.15 & 0.4649 & 1.2669 & 0.86 & 12.3215 & 0.0307 & 0.99 & 0.6195 \\
\hline & & 323.15 & 0.4565 & 1.2645 & 0.86 & 12.2803 & 0.0302 & 0.99 & 0.6231 \\
\hline & \multirow[t]{3}{*}{ Benzalkonium chloride } & 303.15 & 0.7082 & 1.7567 & 0.97 & 5.6478 & 0.0902 & 0.99 & 0.3566 \\
\hline & & 313.15 & 0.7072 & 1.7578 & 0.97 & 5.6394 & 0.0901 & 0.99 & 0.3568 \\
\hline & & 323.15 & 0.7077 & 1.7591 & 0.97 & 5.6389 & 0.0901 & 0.99 & 0.3569 \\
\hline \multirow[t]{6}{*}{ S-bentonite } & \multirow[t]{3}{*}{ Triclosan } & 303.15 & 0.4894 & 1.2704 & 0.87 & 12.5316 & 0.0319 & 0.99 & 0.6103 \\
\hline & & 313.15 & 0.4861 & 1.2695 & 0.87 & 12.5076 & 0.0318 & 0.99 & 0.6114 \\
\hline & & 323.15 & 0.4850 & 1.2697 & 0.87 & 12.5028 & 0.0317 & 0.99 & 0.6121 \\
\hline & \multirow[t]{3}{*}{ Benzalkonium chloride } & 303.15 & 0.7098 & 1.7571 & 0.97 & 5.6528 & 0.0904 & 0.99 & 0.3561 \\
\hline & & 313.15 & 0.7081 & 1.7561 & 0.97 & 5.6495 & 0.0902 & 0.99 & 0.3566 \\
\hline & & 323.15 & 0.7073 & 1.7557 & 0.97 & 5.6448 & 0.0902 & 0.99 & 0.3566 \\
\hline
\end{tabular}

Table 4

Thermodynamic parameters for benzalkonium chloride and triclosan adsorption in single systems onto bentonite and TTA-bentonite.

\begin{tabular}{|c|c|c|c|c|c|c|c|}
\hline \multirow[t]{2}{*}{ Adsorbent } & \multirow[t]{2}{*}{$T(\mathrm{~K})$} & \multicolumn{3}{|c|}{ Benzalkonium chloride } & \multicolumn{3}{|l|}{ Triclosan } \\
\hline & & $\Delta \mathrm{G}^{\circ}(\mathrm{kJ} / \mathrm{mol})$ & $\Delta \mathrm{S}^{\circ}(\mathrm{kJ} / \mathrm{mol} \mathrm{K})$ & $\Delta \mathrm{H}^{\circ}(\mathrm{kJ} / \mathrm{mol})$ & $\Delta \mathrm{G}^{\circ}(\mathrm{kJ} / \mathrm{mol})$ & $\Delta \mathrm{S}^{\circ}(\mathrm{kJ} / \mathrm{mol} \mathrm{K})$ & $\Delta \mathrm{H}^{\circ}(\mathrm{kJ} / \mathrm{mol})$ \\
\hline Pristine bentonite & $\begin{array}{l}303.15 \\
313.15 \\
323.15\end{array}$ & $\begin{array}{l}-4.7175 \\
-4.8758 \\
-5.0341\end{array}$ & 0.0158 & -0.0821 & $\begin{array}{l}-4.4773 \\
-4.6127 \\
-4.7481\end{array}$ & 0.0135 & -0.3732 \\
\hline DTA-bentonite & $\begin{array}{l}303.15 \\
313.15 \\
323.15\end{array}$ & $\begin{array}{l}-4.6906 \\
-4.8452 \\
-4.9998\end{array}$ & 0.0155 & -0.0359 & $\begin{array}{l}-4.5133 \\
-4.6518 \\
-4.7901\end{array}$ & 0.0138 & -0.3178 \\
\hline S-bentonite & $\begin{array}{l}303.15 \\
313.15 \\
323.15\end{array}$ & $\begin{array}{l}-4.6919 \\
-4.8456 \\
-4.9994\end{array}$ & 0.0154 & -0.0313 & $\begin{array}{l}-4.5260 \\
-4.6730 \\
-4.8201\end{array}$ & 0.0147 & -0.0676 \\
\hline
\end{tabular}

satisfactorily an advanced computer is required to perform a complex algorithm such as those in the ideal adsorption solution theory (IAST) and its modified forms, fast-IAS and real adsorption solution theory (RAST).

On the other hand, extended-Langmuir offers the simple isotherm models that adequately built on the thermodynamic and kinetic basis to describe multicomponent adsorption equilibria. Competitive adsorption in the multicomponent system of this study is simply described by the extended Langmuir isotherm in these following mathematical equations:

$q_{e, 1}=\frac{q_{m, 1} \cdot K_{L, 1} \cdot C_{e, 1}}{1+K_{L, 1} \cdot C_{e, 1}+K_{L, 2} \cdot C_{e, 2}}$

$q_{e, 2}=\frac{q_{m, 2} \cdot K_{L, 2} \cdot C_{e, 2}}{1+K_{L, 1} \cdot C_{e, 1}+K_{L, 2} \cdot C_{e, 2}}$

where $q_{m, 1}$ and $q_{m, 2}$ are the maximum sorption capacity of adsorbent for TCS and BAC, while $K_{L, 1}$ and $K_{L, 2}$ are adsorption affinity constants of TCS and BAC, respectively. All Langmuir parameters $\left(q_{m, 1}, q_{m, 2}, K_{L, 1}\right.$ and $\left.K_{L, 2}\right)$ are obtained from single adsorption isotherm data of each component and introduced to Eqs. (7) and (8) for calculating the predicted $q_{e}$ values of each component. To assess the fitting, an error calculation between predicted and measured $q_{\mathrm{e}}$ values is performed. Although extended-Langmuir model has been reported successfully in predicting liquid phase binary adsorption equilibrium data just based on the minimal error between predicted and measured, such approach still lacks in reflecting the involvement of the competition between adsorbate molecules in the solution and on the active surface sites. Therefore, a few slight mathematical modification should be proposed to improve the accuracy of predictions and theoretical basis of the extended-Langmuir model.

In the binary adsorption, the active sorption sites on the solid surface are occupied by two kinds of adsorbate molecule with a specific coverage reflecting its competition effect. The competition may arise until a certain component prevails from the other, but the total monolayer surface coverage by both components should not exceed unity as postulated by the basic Langmuir equation. The competition then can be depicted by natural logarithmic plots that reflect the equilibrium condition of the single adsorption and the competition itself. Therefore, the binary maximum sorption capacity in the equilibrium condition can be assumed equal to the log mean value of each maximum sorption capacity of the solute in single adsorption system that can be formulated mathematically as follows:

$q_{m, \text { bin }}=\frac{q_{m, 2(\text { single })}-q_{m, 1(\text { single })}}{\ln \left(\frac{q_{m, 2(\text { ingle })}}{q_{m, 1 \text { (single })}}\right)}$, with $\quad q_{m, 2(\text { single })}>q_{m, 1 \text { (single }}$

The affinity constant $\left(K_{L}\right)$ measures the attraction strength of the adsorbate molecule towards the surface active site that is the higher the affinity, the adsorbate molecules that tend to cover the surface. Since the competition of adsorbate components in the binary adsorption system existed, the affinity of each 
Table 5

Sum of square error (SSE) values for the extended Langmuir and its modified model of the binary adsorption of benzalkonium chloride and triclosan at various mixtures and temperatures.

\begin{tabular}{|c|c|c|c|c|c|c|c|}
\hline \multirow[t]{2}{*}{ Adsorbent } & \multicolumn{2}{|c|}{ Initial concentration $(\mu \mathrm{mol} / \mathrm{L})$} & \multirow[t]{2}{*}{$T(\mathrm{~K})$} & \multicolumn{2}{|c|}{ Extended Langmuir } & \multicolumn{2}{|c|}{ Modified extended Langmuir } \\
\hline & $C_{o, \text { triclosan }}$ & $C_{o, \text { benzalkoniumchloride }}$ & & $\mathrm{SSE}_{\text {triclosan }}$ & SSE $_{\text {benzalkoniumchloride }}$ & $\mathrm{SSE}_{\text {triclosan }}$ & SSE $_{\text {benzalkoniumchloride }}$ \\
\hline \multirow[t]{9}{*}{ Pristine bentonite } & 20 & 20 & \multirow[t]{3}{*}{303.15} & 10.440970 & 0.157378 & 0.000284 & 0.0003886 \\
\hline & 20 & 15 & & 20.133187 & 0.237884 & 0.000151 & 0.000298 \\
\hline & 20 & 10 & & 38.450752 & 0.759162 & 0.000119 & 0.000260 \\
\hline & 20 & 20 & \multirow[t]{3}{*}{313.15} & 9.814283 & 0.172429 & 0.000161 & 0.000350 \\
\hline & 20 & 15 & & 19.076506 & 0.196068 & 0.000190 & 0.000295 \\
\hline & 20 & 10 & & 36.571842 & 0.693595 & 0.000117 & 0.000394 \\
\hline & 20 & 20 & \multirow[t]{3}{*}{323.15} & 9.230475 & 0.197028 & 0.000289 & 0.000155 \\
\hline & 20 & 15 & & 18.035454 & 0.163540 & 0.000171 & 0.000201 \\
\hline & 20 & 10 & & 34.781394 & 0.625388 & 0.000242 & 0.000242 \\
\hline \multirow[t]{9}{*}{ DTA-bentonite } & 20 & 20 & \multirow[t]{3}{*}{303.15} & 15.020413 & 0.311061 & 0.000310 & 0.000430 \\
\hline & 20 & 15 & & 27.499932 & 0.794490 & 0.000353 & 0.000341 \\
\hline & 20 & 10 & & 50.375994 & 1.372068 & 0.000145 & 0.000241 \\
\hline & 20 & 20 & \multirow[t]{3}{*}{313.15} & 14.960781 & 0.289328 & 0.000198 & 0.000149 \\
\hline & 20 & 15 & & 27.234831 & 0.755964 & 0.000179 & 0.000445 \\
\hline & 20 & 10 & & 50.000504 & 1.318352 & 0.000144 & 0.000423 \\
\hline & 20 & 20 & \multirow[t]{3}{*}{323.15} & 14.808665 & 0.310190 & 0.000270 & 0.000117 \\
\hline & 20 & 15 & & 27.122724 & 0.770065 & 0.000134 & 0.000273 \\
\hline & 20 & 10 & & 49.426541 & 1.274867 & 0.000245 & 0.000279 \\
\hline \multirow[t]{9}{*}{ S-bentonite } & 20 & 20 & \multirow[t]{3}{*}{303.15} & 14.104274 & 0.247219 & 0.000269 & 0.000177 \\
\hline & 20 & 15 & & 25.987715 & 0.681162 & 0.000378 & 0.000115 \\
\hline & 20 & 10 & & 47.568724 & 1.258606 & 0.000160 & 0.000150 \\
\hline & 20 & 20 & \multirow[t]{3}{*}{313.15} & 13.678340 & 0.231163 & 0.001198 & 0.001686 \\
\hline & 20 & 15 & & 25.186422 & 0.660619 & 0.000245 & 0.000588 \\
\hline & 20 & 10 & & 46.456712 & 1.223793 & 0.000772 & 0.001807 \\
\hline & 20 & 20 & \multirow[t]{3}{*}{323.15} & 13.314371 & 0.238611 & 0.000249 & 0.000161 \\
\hline & 20 & 15 & & 24.536537 & 0.640252 & 0.000111 & 0.000281 \\
\hline & 20 & 10 & & 45.318928 & 1.198186 & 0.000116 & 0.014387 \\
\hline
\end{tabular}

component should be weaker than those in the single adsorption system making the direct use of the single adsorption affinity constant to be invalid. Therefore, the $K_{L}$ from single isotherm data could be corrected by the equations below:

$K_{L, 1 \text { (bin) }}=K_{L, 1 \text { (single })}\left(\frac{\Delta G_{1}^{\circ}(\text { single }) \times C_{0,1}}{\Delta G_{1}^{\circ}(\text { single }) \times C_{0,1}+\Delta G_{2}^{\circ}(\text { single }) \times C_{0,2}}\right)$

$K_{L, 2(\text { bin })}=K_{L, 2(\text { single })}\left(\frac{\Delta G_{2}^{\circ}(\text { single }) \times C_{0,2}}{\Delta G_{1}^{\circ}(\text { single }) \times C_{0,1}+\Delta G_{2}^{\circ}(\text { single }) \times C_{0,2}}\right)$

In Eqs. (9) and (10), the competitive behavior of the adsorbate components are expressed as the ratio of the multiplication value between standard Gibb's free energy change and initial concentration of certain adsorbate to the summation of those values for both components. It can be noticed that in Eqs. (10) and (11), the adsorption affinity of an adsorbate species in the binary adsorption system is reduced from its adsorption affinity in the single adsorption system by the presence of adsorbates competition. Introduction of the initial concentration of the adsorbate species in this equation represents the increasing tendency of adsorption affinity or the shifting act of equilibrium condition towards the adsorption along with the increasing initial concentration, which is in conformance with the Le Chatelier's principle. Here, the standard Gibb's free energy is constrained to be less than or equal to zero, which also means that only the spontaneous one is concerned to the competition phenomena.

Substitution of Eqs. (9)-(11) into Eqs. (7) and (8) gives the following mathematical expressions:

$q_{e, 1(\mathrm{bin})}=\frac{q_{m, \mathrm{bin}} \cdot K_{L, 1(\mathrm{bin})} \cdot C_{e, 1(\mathrm{bin})}}{1+K_{L, 1(\mathrm{bin})} \cdot C_{e, 1(\mathrm{bin})}+K_{L, 2(\mathrm{bin})} \cdot C_{e, 2(\mathrm{bin})}}$ $q_{e, 2(\mathrm{bin})}=\frac{q_{m, \mathrm{bin}} \cdot K_{L, 2(\mathrm{bin})} \cdot C_{e, 2(\mathrm{bin})}}{1+K_{L, 1(\mathrm{bin})} \cdot C_{e, 1(\mathrm{bin})}+K_{L, 2(\mathrm{bin})} \cdot C_{e, 2(\mathrm{bin})}}$

Eqs. (12) and (13) are assigned as the modified extendedLangmuir isotherm model in this study, and its prediction performance is tested in terms of the sum of square error towards the experimental binary adsorption isotherm data. The quantification of adsorbed equilibrium capacity and its sum of square error (SSE) against the experimental data are performed by Microsoft Office Excel 2007. To observe the improvisation, the SSE values of the predicted equilibrium adsorption capacity from the original extended Langmuir model are also counted.

The result of the SSE quantification is summarized in Table 5, while some representation plots that show the aptness between the calculated and experimental adsorption data are illustrated in Fig. 3. The incorporation of the log mean value of maximum adsorption capacity and the Gibb's free energy ratio in the extended Langmuir model gave better representation of the experimental data than the original extended Langmuir model as indicated in Table 5 and Fig. 3. Judging from the SSE, original extended Langmuir equation produces relatively small error only on the adsorption of BAC that can be presumed as its limited well-reputed capability in performing binary adsorption data prediction of a component with a high affinity relative to its molecular competitor while the modified extended Langmuir is capable to predict both adsorbates system due to the incorporation of the thermodynamical favorability ratio, which may give a proportional relative affinity of an adsorbate to the adsorbent surface. In the real experimental data view, the competition between adsorbate species during the adsorption was indicated by the decreasing adsorbed amount, whereas the presence of either BAC or TCS decrease the uptake capacity of the other relative to the single adsorption data. However, it should be noticed that the significance decrease on TCS uptake is observed on the organo-bentonite (i.e., S-bentonite and DTA-bentonite), while 


\section{Extended Langmuir}
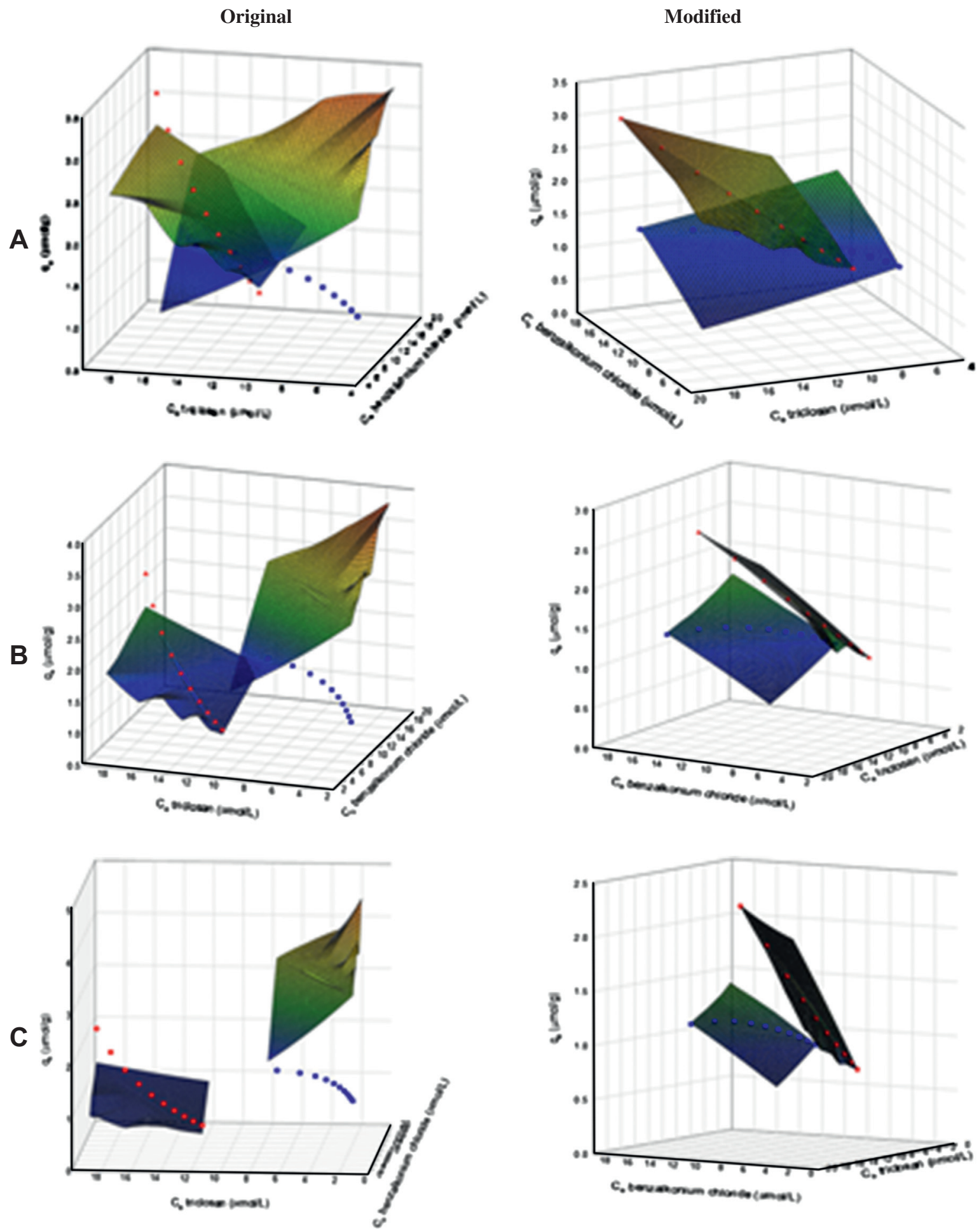

Fig. 3. The aptness of original and modified extended Langmuir models against experimental binary adsorption data of benzalkonium chloride (BAC- $\bullet$ ) and triclosan (TCS- -1 ) at $303.15 \mathrm{~K}$ onto S-bentonite using. (A) $C_{o}$ benzalkonium chloride $=20 \mu \mathrm{mol} / \mathrm{L}, C_{o}$ triclosan $=20 \mu \mathrm{mol} / \mathrm{L}$, (B) $C_{o}$ benzalkonium chloride $=15 \mu \mathrm{mol} / \mathrm{L}, C_{o}$ triclosan $=20 \mu \mathrm{mol} / \mathrm{L},(C)$ $C_{o}$ benzalkonium chloride $=10 \mu \mathrm{mol} / \mathrm{L}, C_{o}$ triclosan $=20 \mu \mathrm{mol} / \mathrm{L}$.

the decreasing the BAC uptake is seen on the pristine bentonite. This could be possible because of the nature of each adsorption affinity, that is, a strong adsorption affinity of certain species on either pristine or organo-bentonite contributes an ability to preserve its uptake in the middle of molecular competition.

\section{Conclusions}

Removal of micro-pollutant compounds, namely, benzalkonium chloride (BAC) and triclosan (TCS) from synthetic wastewater was studied using pristine and organo-bentonite. The organo-bentonite 
was modified with two kinds of surfactant: synthetic DTAB surfactant and natural saponin surfactant under microwave irradiation. Microwave irradiation contributes positive effect on the intercalation of organic cation that can be seen by interlamellar space broadening and pore blockage. The uptake capacity of the BAC is at its greatest point when it is adsorbed by the pristine bentonite while the maximum adsorption of TCS is achieved by applying the organo-bentonite. The optimum $\mathrm{pH}$ for both adsorption is lied on the slightly acidic condition ( $\mathrm{pH}$ of 6 ). The Langmuir model for single component adsorption and the thermodynamically modified extended Langmuir model are able to represent the single and binary component adsorption data, respectively.

\section{Acknowledgement}

This work was supported by Directorate General of Higher Education, Indonesia Ministry of Culture and Education through Competency Research Grant 2013 with contract number of 050/ SP2H/PL/DIT.LITABMAS/V/2013.

\section{Appendix A. Supplementary material}

Supplementary data associated with this article can be found, in the online version, at http://dx.doi.org/10.1016/j.cej.2013.12.001.

\section{References}

[1] M.J. Gomez, M.J.M. Bueno, S. Lacorte, A.R. Fernandez-Alba, A. Aguera, Pilot survey monitoring pharmaceuticals and related compounds in a sewage treatment plant located on the Mediterranean coast, Chemosphere 66 (2007) 993-1002.

[2] A.B. Dann, A. Hontela, Triclosan: environmental exposure, toxicity and mechanisms of action, J. Appl. Toxicol. 31 (2011) 285-311.

[3] U. Tezel, S.G. Pavlostathis, Role of quaternary ammonium compounds on antimicrobial resistance in the environment, in: P.L. Keen, M.H.M.M Montforts (Eds.), Antimicrobial Resistance in the Environment, WileyBlackwell, New Jersey, 2012, pp. 349-388.

[4] R. Szczepanowski, T. Bekel, A. Goesmann, L. Krause, H. Kromeke, O. Kairser, W. Eichler, A. Puhler, A. Schluter, Insight into the plasmid metagenome of wastewater treatment plant bacteria showing reduced susceptibility to antimicrobial drugs analysed by the 454-pyrosequencing technology, J. Biotechnol. 136 (2008) 54-64.

[5] A. Rajkovic, N. Smigic, M. Uyttendaele, H. Medic, L.d. Zutter, F. Devlieghere, Resistance of Listeria monocytogenes, Escherichia coli 0157:H7 and
Campylobacter jejuni after exposure to repetitive cycles of mild bactericidal treatments, Food Microbiol. 26 (2009) 889-895.

[6] O. Condell, C. Iversen, S. Cooney, K.A. Power, C. Walsh, C. Burgess, S. Fanning, Efficacy of biocides used in the modern food industry to control Salmonella enterica, and links between biocide tolerance and resistance to clinically relevant antimicrobial compounds, Appl. Environ. Microbiol. 78 (2012) 30873097.

[7] J.M. Buth, P.O. Steen, C. Sueper, D. Blumentritt, P.J. Vikesland, W.A. Arnold, K. Mcneill, Dioxin photoproducts of triclosan and its chlorinated derivatives in sediment cores, Environ. Sci. Technol. 44 (2010) 4545-4551.

[8] N. Tatarazako, H. Ishibashi, K. Teshima, K. Kishi, K. Arizono, Effects of triclosan on various aquatic organisms, Environ. Sci. 11 (2004) 133-140.

[9] K.L. Rule, V.R. Ebbett, P.J. Vikesland, Formation of chloroform and chlorinated organics by free-chlorine-mediated oxidation of triclosan, Environ. Sci. Technol. 39 (2005) 3176-3185.

[10] N. Klamerth, S. Malato, M.I. Maldonado, A. Aguera, A.R. Fernandez-Alba, Application of photo-Fenton as a tertiary treatment of emerging contaminants in municipal wastewater, Environ. Sci. Technol. 44 (2010) 1792-1798.

[11] L. Kovalova, H. Siegrist, H. Singer, A. Wittmer, C.S. McArdell, Hospita wastewater treatment by membrane bioreactor: performance and efficiency for organic micropollutant elimination, Environ. Sci. Technol. 46 (2012) 15361545.

[12] I. Arslan-Alaton, Degradation of a commercial textile biocide with advanced oxidation processes and ozone, J. Environ. Manage. 82 (2007) 145-154.

[13] C. Noutsopoulos, D. Mamais, V. Samaras, T. Bouras, M. Marneri, K. Antoniou, Effect of wastewater chlorination on endocrine disruptor removal, Water Sci. Technol. 67 (2013) 1551-1556.

[14] L. Hernandez-Leal, H. Temmink, G. Zeeman, C.J. Buisman, Removal of micropollutants from aerobically treated greywater via ozone and activated carbon, Water Res. 45 (2011) 2887-2896.

[15] M. Grassi, L. Rizzo, A. Farina, Endocrine disruptors compounds, pharmaceuticals and personal care products in urban wastewater: Implications for agricultural reuse and their removal by adsorption process, Environ. Sci. Pollut. Res. 20 (2013) 3616-3628.

[16] A.K. Rahardjo, M.J.J. Susanto, A. Kurniawan, N. Indraswati, S. Ismadji, Modified ponorogo bentonite for the removal of ampicillin from wastewater, J. Hazard. Mater. 190 (2011) 1001-1009.

[17] S.M. Lee, D. Tiwari, Organo and inorgano-organo-modified clays in the remediation of aqueous solutions: an overview, Appl. Clay Sci. 59-60 (2012) 84-102.

[18] A. Kurniawan, H. Sutiono, Y.-H. Ju, F.E. Soetaredjo, A. Ayucitra, A. Yudha, S. Ismadji, Utilization of rarasaponin natural surfactant for organo-bentonite preparation: application for methylene blue removal from aqueous effluent, Micropor. Mesopor. Mater. 142 (2011) 184-193.

[19] J.J.M. Orfao, A.I.M. Silva, J.C.V. Pereira, S.A. Barata, I.M. Fonseca, P.C.C. Faria M.F.R. Pereira, Adsorption of reactive dye on chemically modified activated carbon-influence of pH, J. Colloid Interface Sci. 296 (2006) 480-489.

[20] T.W. Weber, R.K. Chakravorti, Pore and Solid diffusion models for fixed-bed adsorbers, AIChe J. 20 (1974) 228-238.

[21] G. Borchardt, Smectites, in: J.B. Dixon, S.B. Weed (Eds.), Minerals in Soil Environments, Soil Science Society of America, Madison, 1989, pp. 675-727.

[22] A.A. Khan, R.P. Singh, Adsorption thermodynamics of carbofuran on Sn(IV) arsenosilicate in $\mathrm{H}^{+}, \mathrm{Na}^{+}$and $\mathrm{Ca}^{2+}$ forms, Colloids Surf. 24 (1987) 33-42. 